\title{
Large scale integrated hydrological modelling of the impact of climate change on the water balance with DANUBIA
}

\author{
M. Prasch ${ }^{1}$, T. Marke ${ }^{1, *}$, U. Strasser ${ }^{1, *}$, and W. Mauser ${ }^{1}$ \\ ${ }^{1}$ Department of Geography, Ludwig-Maximilians-Universität Munich, Germany \\ * now at: Institute of Geography and Regional Science, University of Graz, Austria
}

\begin{abstract}
Future climate change will affect the water availability in large areas. In order to derive appropriate adaptation strategies the impact on the water balance has to be determined on a regional scale in a high spatial and temporal resolution. Within the framework of the BRAHMATWINN project the model system DANUBIA, developed within the project GLOWA Danube (GLOWA Danube, 2010; Mauser and Ludwig, 2002), was applied to calculate the water balance components under past and future climate conditions in the large-scale mountain watersheds of the Upper Danube and the Upper Brahmaputra. To use CLM model output data as meteorological drivers DANUBIA is coupled with the scaling tool SCALMET (Marke, 2008). For the determination of the impact of glacier melt water on the water balance the model SURGES (Weber et al., 2008; Prasch, 2010) is integrated into DANUBIA. In this paper we introduce the hydrological model DANUBIA with the tools SCALMET and SURGES. By means of the distributed hydrological time series for the past from 1971 to 2000 the model performance is presented. In order to determine the impact of climate change on the water balance in both catchments, time series from 2011 to 2080 according to the IPCC SRES emission scenarios A2, A1B, B2 and Commitment are analysed. Together with the socioeconomic outcomes (see Chapter 4) the DANUBIA model results provide the basis for the derivation of Integrated Water Resources Management Strategies to adapt to climate change impacts (see Chapter 9 and 10).
\end{abstract}

\section{Introduction and objectives}

The impact of climate change on the water resources is one of the most essential issues for the population of mountain areas and their forelands in the future (Barnett et al., 2005). In order to determine the impact of future climate change on the water balance and to identify appropriate adaptation strategies (see Chapter 9 and 10), the main objective of the hydrological modelling was to deliver distributed hydrological time series for historical as well as future climate conditions in the large mountain watersheds of the Upper Danube and the Upper Brahmaputra on a proper temporal and spatial resolution. Therefore the model DANUBIA, developed within the research project GLOWA-Danube (GLOWA Danube, 2010; Mauser and Ludwig, 2002), was applied in the framework of the project BRAHMATWINN in both basins. In order to use the outcomes of the regional climate model CLM (see Chapter 2) as meteorological drivers, a further

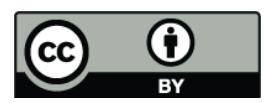

Correspondence to: $\mathrm{M}$. Prasch

(m.prasch@iggf.geo.uni-muenchen.de) downscaling of the climate model outcomes was carried out wit the tool SCALMET (Marke, 2008). The analysis of the model results should explicitly comprise the impact of snow and glacier melt on the water balance in respect to climate change, so that glacier dynamics had to be modelled in an appropriate way. In this paper we introduce the hydrological model DANUBIA with the tools SCALMET and SURGES. At first, the model performance is shown. Afterwards the analysis of the model results with respect to the impact of climate change on the water balance is presented.

\section{Role within the integrated project}

The hydrological modelling with DANUBIA enables the simulation of distributed hydrological dynamics in a high spatial and temporal resolution. Since the model is based on physical principles and is not calibrated to measured discharges it can be applied in regions with different environmental conditions for past as well as for future climatic conditions. The analysis of the time series of the water balance components for the time period from 1971 to 2080, 
provided by DANUBIA, enables the determination of the influence of climate change on water balance components and accordingly on the water availability at the regional scale. As four different IPCC SRES scenarios (see Chapter 2) are used as meteorological drivers, a range of possible future trends is given. Together with the outcomes of the socio-economic modelling the DANUBIA model results provide the basis for the development of the Integrated Water Resources Management Strategies IWRMS as one of the ultimate outcomes of BRAHMATWINN.

\section{Scientific methods applied}

Hydrological models should fulfil several requirements to determine the impact of climate change on the water balance in large-scale watersheds. The spatial heterogeneity of complex basins with mountain headwatersheds as the Alps or the Himalaya on the one hand and mountain forelands with large river valleys like the Brahmaputra or the Danube on the other hand have to be captured synchronously by the model. This includes the ability to simulate the relevant processes under different climatic conditions as well as varying hydrological regimes (Mauser and Bach, 2009). Therefore process based spatially distributed models were developed which can be divided into two groups. The first group considers hydrological homogenous areas as hydrological response units (HRU) (Leavesley et al., 1983; Flügel, 1996), whereas the second is based on spatial grids, where spatial as well as linear hydrological processes are modelled with a consistent data set (e.g. Lee et al., 2005; Mauser and Bach, 2009). The latter models have the advantage that the coupling with climate models is easier, because climate models usually are also raster-based. A further requirement for the coupling is to close the energy and mass balance within all model components. Therefore in the framework of BRAHMATWINN the integrative decision support system (DSS) DANUBIA was applied in the UDRB as well as the UBRB. The DSS consists of both socio-economic and natural process models which are coupled to consider the interactions between socioeconomics and nature. The physically based, fully spatially distributed model PROMET (Processes of Radiation, Mass and Energy Transfer) (Mauser and Bach, 2009) builds the landsurface core model of DANUBIA for the simulation of the natural processes. PROMET was developed as a raster model with a spatial resolution of $1 \times 1 \mathrm{~km}$ and runs on an hourly time step. It strictly conserves mass and energy within as well as throughout all its components and feedbacks. So all processes related to water fluxes of complex watersheds are considered in fully interacting components for meteorology, land surface energy and mass balance, vegetation, snow and ice, soil hydraulics and soil temperature as well as in a groundwater and channel-flow component with hydraulic structures. PROMET is not calibrated using measured discharges to fully exploit the predictive capabilities of

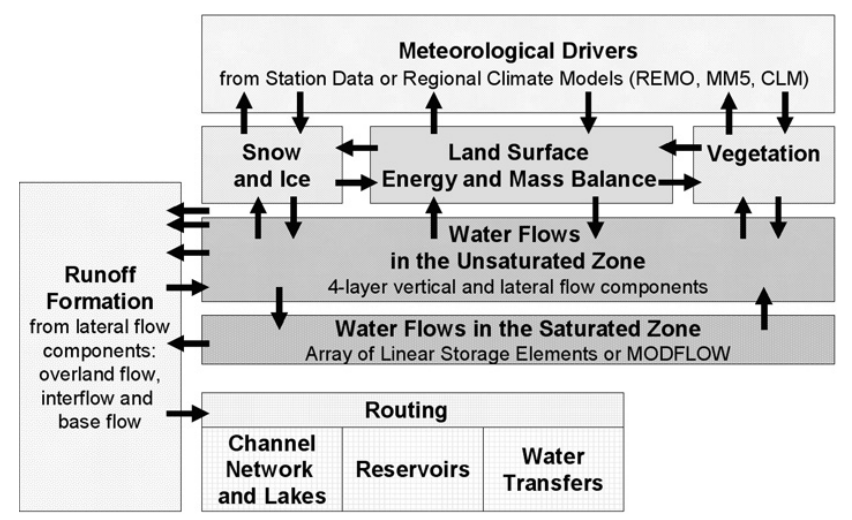

Figure 1. Schematic diagram of the components of PROMET, the DANUBIA landsurface core model, and the interfaces between them. Boxes indicate components and arrows indicate interfaces, through which data is exchanged (Mauser and Bach, 2009, p. 365).

the physically based approach. Figure 1 gives a schematic overview of the mentioned components and its interfaces for data exchange (Mauser and Bach, 2009).

Since the spatial resolution of climate models is still limited, e.g. the CLM has a resolution of $50 \times 50 \mathrm{~km}$, land surface heterogeneities cannot be considered properly, so that for example the topography especially in high mountain areas and accordingly the environmental variability is not fully captured by the RCMs. As a consequence, the impact of climate change cannot be investigated at a local scale (Gerstengarbe, 2001). In order to bridge the scales, basically two downscaling techniques are used. The dynamical technique is based on physics and enables the consideration of small scale climate processes (Gerstengarbe, 2001), whereas the statistical downscaling uses empirical relations. In most cases, both downscaling techniques are combined as it is done by the tool SCALMET (Scaling Meteorological variables) (Marke, 2008). To use the provided CLM output (see Chapter 2) at the required resolution for the process description at the landsurface $(1 \times 1 \mathrm{~km})$ a further downscaling was applied to the model output with SCALMET. As shown in Fig. 2, SCALMET connects models simulating the atmosphere with those operating at the land surface. In order to reflect the natural climate gradients more realistically, SCALMET uses globally available sub-grid information (e.g. terrain elevation, topographic slope and aspect) in a spatial resolution of $1 \times 1 \mathrm{~km}$ to adjust the RCM model output. A regression approach is applied to adjust those meteorological variables with respect to sub-grid topography that strongly vary with terrain elevation, e.g. air temperature. For the remapping of wind speed and long- and shortwave radiation, separate submodels have been implemented in the coupler to account for sub-grid heterogeneities within the remapping process. Furthermore, a temporal interpolation routine to disaggregate the $3 \mathrm{~h}$ values of the CLM output to an hourly time basis is implemented into SCALMET. To maintain the energy and 


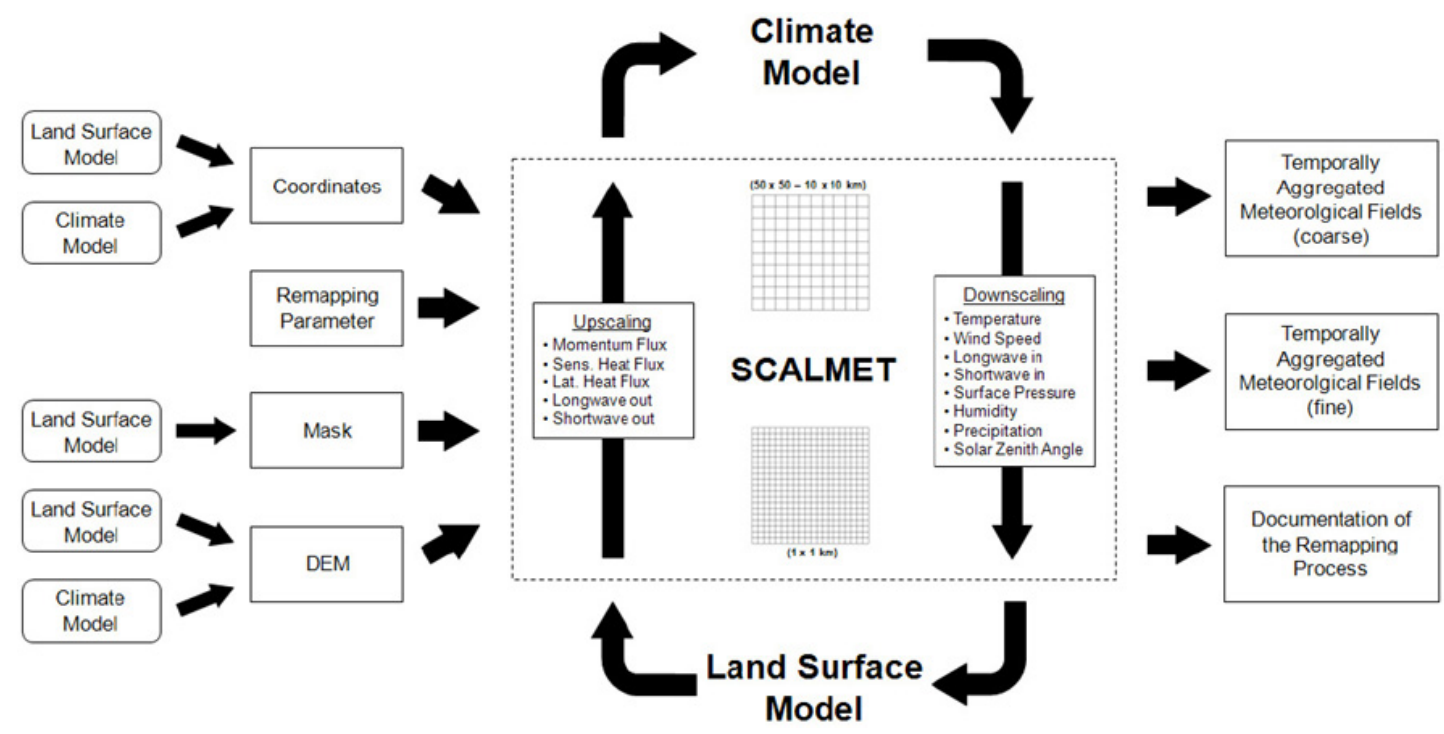

Figure 2. Schematic overview of the coupled model SCALMET (Marke, 2008, p. 41).

mass budged predetermined by the RCM outputs, special algorithms have been integrated that systematically assure the conservation of mass and energy between the model scales. As the downscaling techniques implemented in SCALMET are based on physical and statistical approaches, they are completely general and do not require any further parameterization.

In order to completely describe the hydrological processes, especially in mountain watersheds like the UDRB and the UBRB, the consideration of cryospheric processes is necessary. For the determination of the influence of glaciers under changing climate conditions, various glacier models of different complexity have been developed (Oerlemans, 2008). To numerically describe the glacier melt water release on a raster scale of $1 \mathrm{~km}^{2}$, glacier dynamics have to be considered appropriately by finding a compromise between complex and simple models. For that purpose DANUBIA has been extended with the component SURGES (SUbscale Regional Glacier Extension Simulator) (Weber et al., 2008; Prasch, 2010), simulating glacier advance and retreat utilizing a glacier inventory which provides geometry characteristics for each single glacier. The total area of every glacier is subdivided into equidistant elevation levels with a homogenous ice thickness for all grid cells. In every time step, the hourly meteorological data, provided by DANUBIA is distributed to each subscale level. In this way mass and energy balance can be calculated for every elevation level to model accumulation and ablation and accordingly, quantify the melt water release to runoff. In a simple parameterization, snow metamorphosis and ice flow are also considered in SURGES. Hence, the individual dynamics of any single glacier and the effect of climate change on the ice resources in the Alpine or respectively Himalayan headwatersheds can be investigated. Figure 3 presents a schematic overview of SURGES.

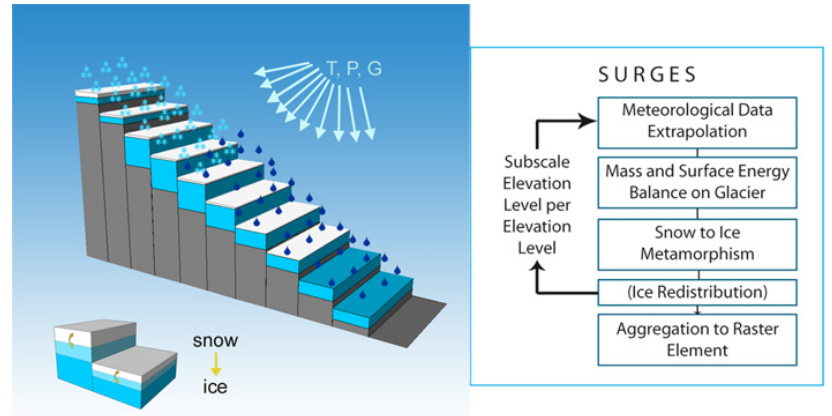

Figure 3. Scheme of the glacier model SURGES, symbolizing the subscale elevation levels of the glacierized area (Weber et al., 2009, modified).

The model framework of DANUBIA including the tools SCALMET and SURGES as explained above fulfils all requirements for the hydrological modelling within BRAHMATWINN to deliver distributed hydrological time series in both test basins for past as well as future climate conditions. Before the model performance and the model results are presented in the following section, the required input data are briefly described.

\section{Results achieved and deliverables provided}

In order to run DANUBIA, input data fields of topography, landuse and landcover, soil texture as well as glacier properties with a spatial resolution of $1 \times 1 \mathrm{~km}$ are required besides meteorological drivers. Furthermore, properties describing soil and landuse/landcover classes have to be provided (Mauser and Bach, 2009). For the UDRB all data were available from the GLOWA-Danube project. For the 

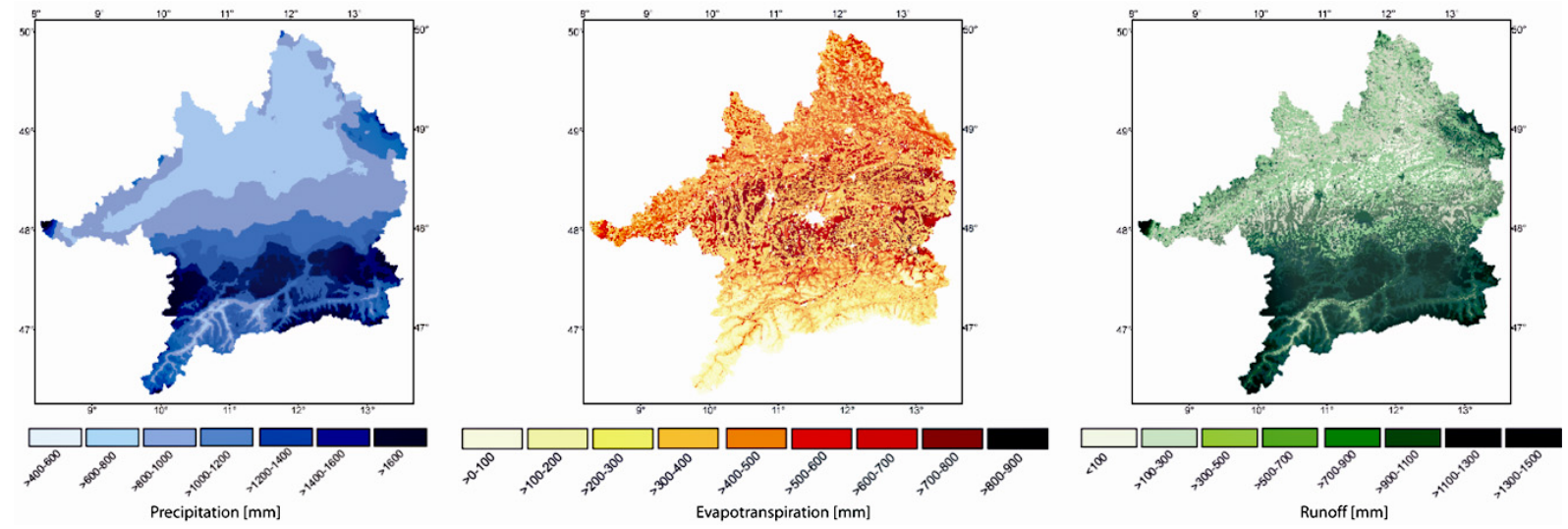

Figure 4. Modelled distributed water balance in the UDRB in using station recordings as meteorological drivers for the period 1971-2000.
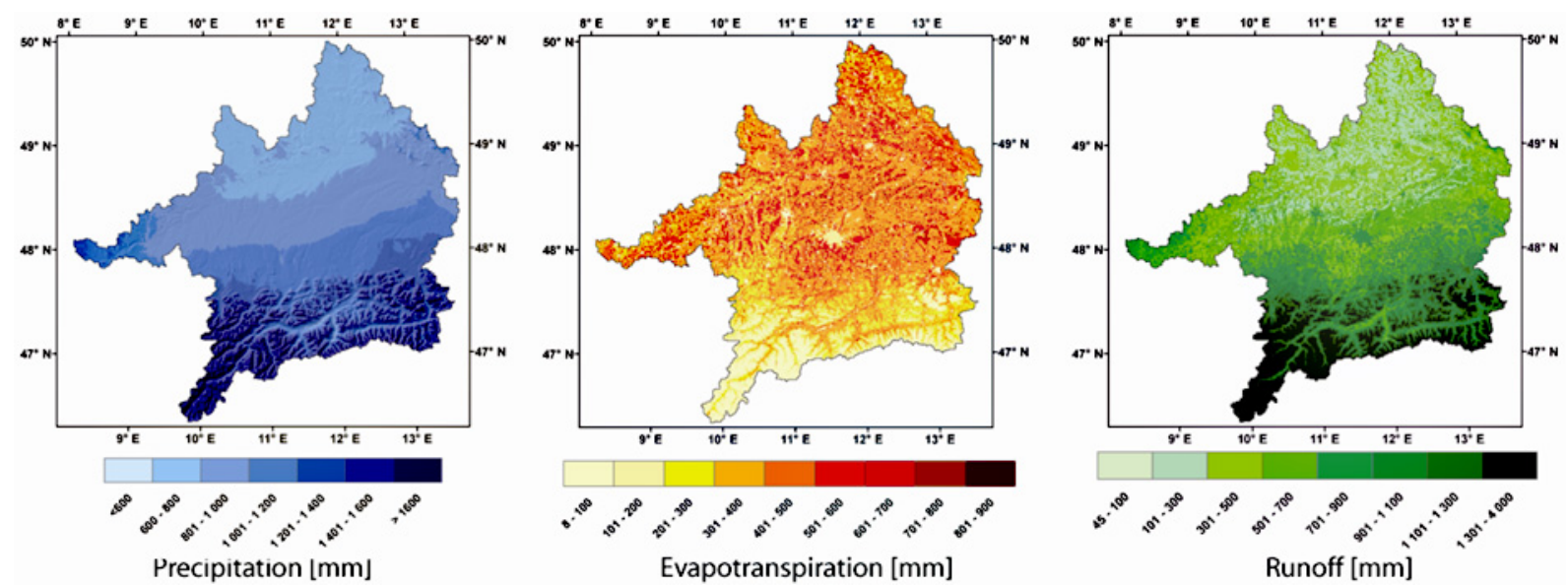

Figure 5. Modelled distributed water balance in the UDRB in using CLM ERA data as meteorological drivers for the period 1971-2000.

UBRB topography was deduced from the SRTM data (Jarvis et al., 2006). To provide a suitable landuse and landcover data set, we use the publically available classification from MODIS/TERRA (Boston University, 2004). The digital Soil Map of the FAO/UNESCO (FAO-UNESCO, 2003) represents the basis for the applied soil texture classification. For the glacier model, the data were derived of the Chinese glacier inventory (WDC, 2009). All data are stored in a raster GIS structure and initialised at the beginning of the modelling. Detailed information of soil physics and plant parameters, stored as data tables, are taken from literature and/or field campaigns. The results of the DANUBIA hydrological model consist of both a specified set of output variables for selectable raster elements and of spatially distributed fields for the catchment area, describing e.g. the water balance and runoff components.

\subsection{The model performance of DANUBIA}

Detailed validation studies of the model DANUBIA and its components were conducted, so that it is referred to Mauser and Bach (2009), Marke (2008), Weber et al. (2008), Prasch (2010) and GLOWA Danube (2010) for further details at this point. In order to check the quality of the hydrological model DANUBIA, driven with CLM model output data and to assess uncertainties, model runs were carried out for the period from 1971 to 2000 for both the UDRB and the UBRB. The simulated water balance of the UDRB is compared to model results driven by meteorological station recordings. In using the latter, about $1039 \mathrm{~mm}$ of precipitation and $430 \mathrm{~mm}$ of evapotranspiration occur on average per year. The difference between precipitation and evapotranspiration results in a modelled runoff of $609 \mathrm{~mm}$. This value resembles the observed discharge of $590 \mathrm{~mm}$ at the catchment outlet gauge of the UDRB in Achleiten near the city of Passau, so that the accuracy of the simulated runoff is in the range of $3 \%$ (Fig. 4). The comparison of modelled with observed daily channel runoff values of the Danube in Achleiten is presented in Fig. 6 (left). A Nash-Sutcliffe efficiency coefficient (Nash and Sutcliffe, 1970) of 0.84 and a coefficient of determination of 0.87 allow the conclusion that DANUBIA can reproduce 

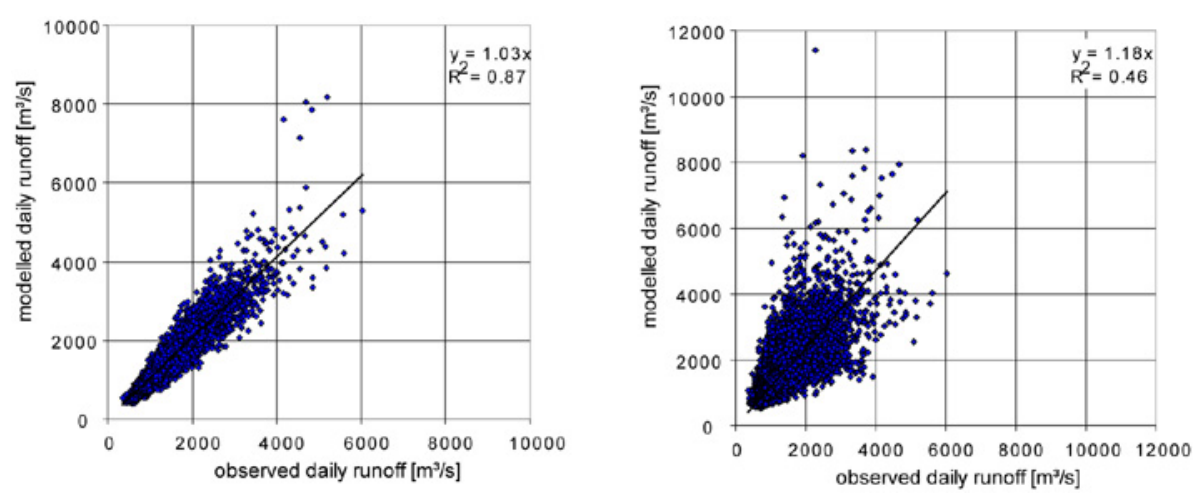

Figure 6. Comparison of observed and modelled daily runoff at the UDRB outlet gauge in Achleiten for 1971-2000, using station recordings (left) and downscaled CLM ERA output data (right).

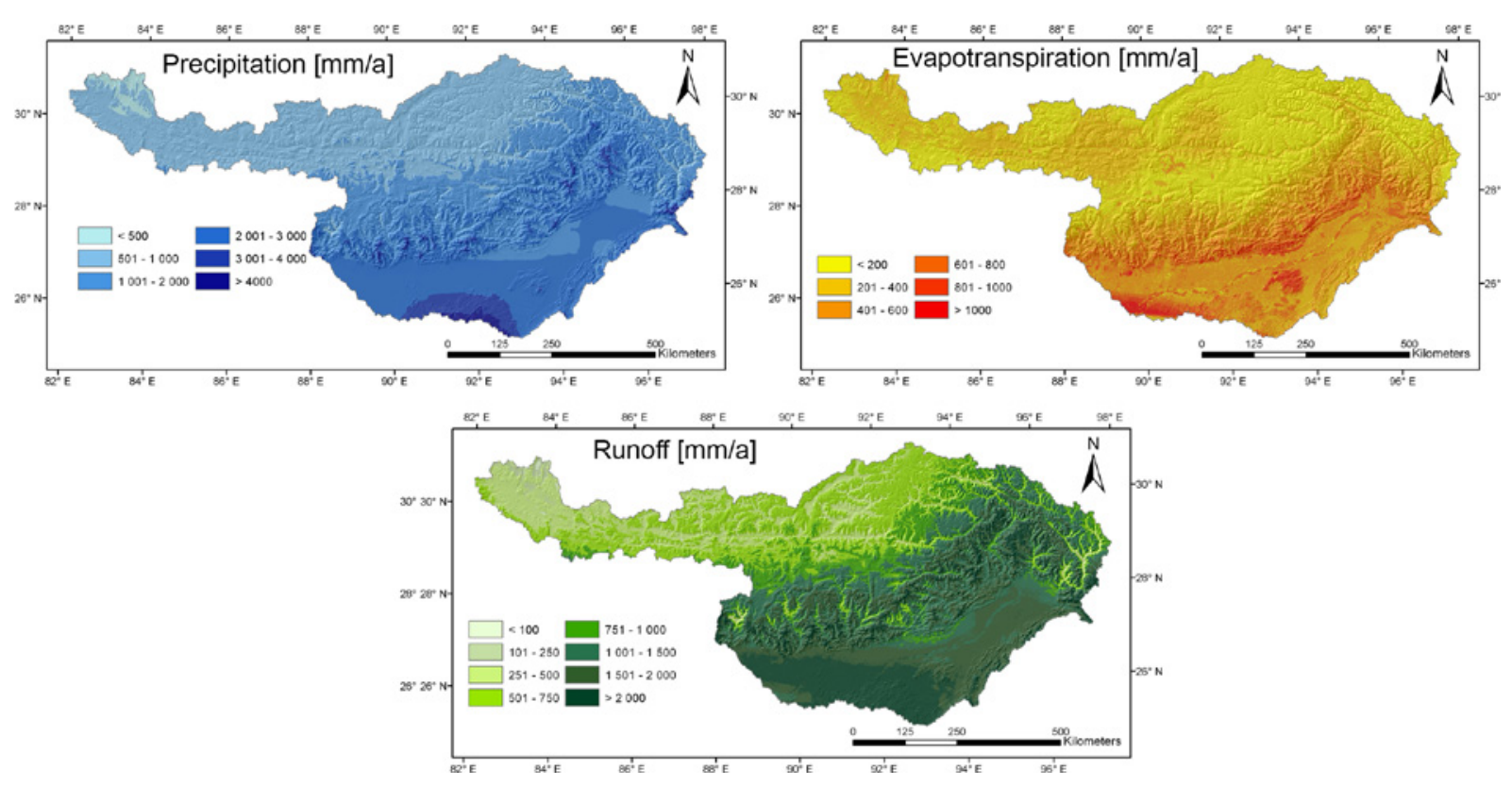

Figure 7. Modelled distributed water balance in the UBRB in using CLM ERA data as meteorological drivers for the period 1971-2000.

the water balance of the past in the UDRB, which is confirmed by the values for other gauges of subcatchments in the UDRB according to Mauser and Bach (2009). Figures 5 and 6 (right) show the similar model results for the water balance in using downscaled CLM ERA output data as meteorological drivers. Compared to the station driven results, precipitation is higher whereas evapotranspiration is lower on average. The spatial distribution of precipitation also is different. Especially the wind and leeside effects at the northern alpine border line are not reproduced by the CLM data. This causes an overestimation of the runoff of 21 percent for the period from 1971-2000 compared to the observed data. Using CLM ECHAM data as meteorological drivers leads to a further overestimation, so that the deviation of the runoff is 26 percent altogether. Although the overestimation affects the daily runoff course, it is reproduced, the coefficient of determination is 0.46 (Fig. 6, right). Reasons for the deviation can be found in the different precipitation pattern of the CLM data and the lower evapotranspiration which can be traced back to the very high air humidity in the data set.

In the UBRB the number of station recordings and the observed data are insufficient to use them as meteorological drivers, so that only CLM data can be used in the Asian catchment. Figure 7 shows the modelled water balance in the UBRB driven by downscaled CLM ERA data for 19712000. About $1550 \mathrm{~mm}$ of precipitation and $320 \mathrm{~mm}$ evapotranspiration occur in average per year. The difference between precipitation and evapotranspiration results in a mean modelled discharge of $19810 \mathrm{~m}^{3} \mathrm{~s}^{-1}$. According to Jain et al. (2007) the average discharge near the confluence of the Brahmaputra with the Ganges River is $19200 \mathrm{~m}^{3} \mathrm{~s}^{-1}$. This 

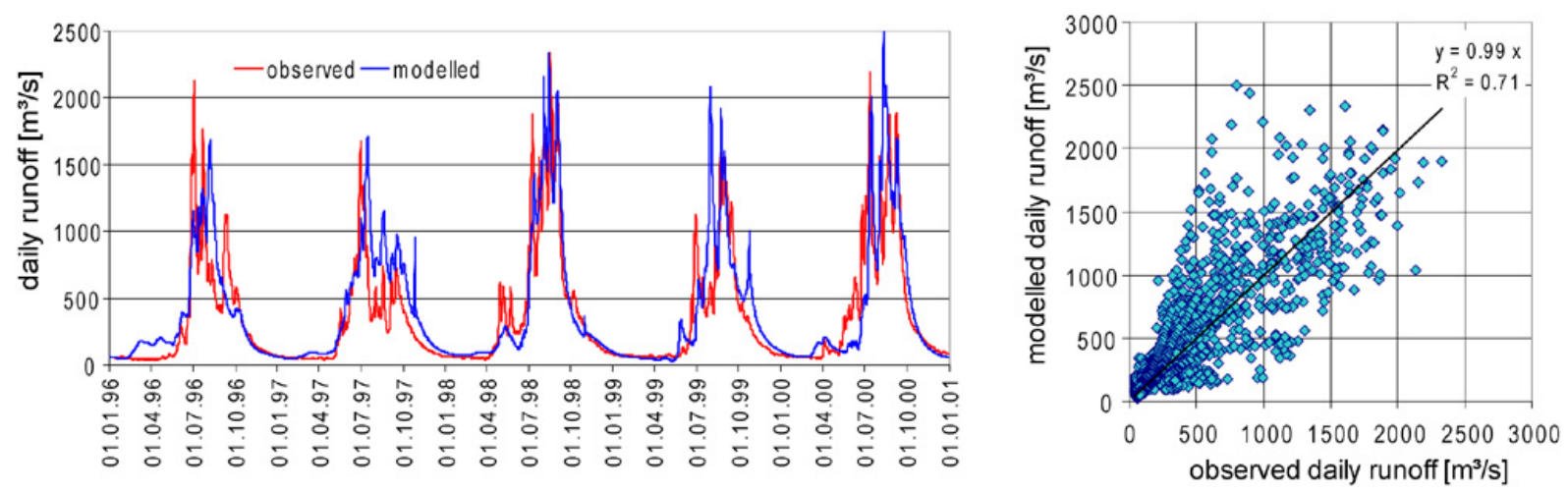

Figure 8. Modelled (CLM ERA driven) and observed monthly runoff at the gauge in Lhasa at the Lhasa River for 1996-2000.

value corresponds very well with the modelled discharge, although in general the latter is slightly overestimated by the model. The spatial distribution shows the subdivision of the UBRB in the dry Tibetan parts north of the Himalayas and the wet southern parts of India and Bhutan with high monsoon precipitation. The varying air temperature due to the different elevation and the different water availability causes low evapotranspiration rates in the north, whereas in the southern parts of the catchment values over $1500 \mathrm{~mm}$ per year can be reached. These values are measured by stations in this region (Singh et al., 2004).

Annual courses of runoff data are sparse in the UBRB, so that modelled and observed runoff values are compared for the subcatchment of the Lhasa River in Tibet. Figure 8 shows the modelled as well as the observed daily runoff at the gauge in Lhasa from 1996 to 2000. The simulated runoff explains 71 percent of the observed runoff, although the quality strongly varies between the years. A Nash-Sutcliffe efficiency coefficient of 0.67 confirms the result. Reasons for the deviations could be manifold. Besides changes in the observation methodology, the precipitation pattern is not fully captured by the CLM ERA model data in some years (see Chapter 2).

Although the model uncertainty increases in using climate model output as meteorological drivers in the hydrological model as shown in the validation steps, the results proof the robustness and applicability of the modelling framework DANUBIA for the project purposes within the bounds of possibility, taking into account several uncertainties of the input data as well as of the observations.

\subsection{The impact of climate change on the water balance}

The regional climate model data of the CLM, driven by the global climate model ECHAM 5, is provided for the four IPCC SRES emission scenarios A2, A1B, B1 and the commitment model run (see Chapter 2). They are used as meteorological drivers for DANUBIA to calculate future time series of the water balance components for the UDRB and the UBRB. In order to determine the impact of future

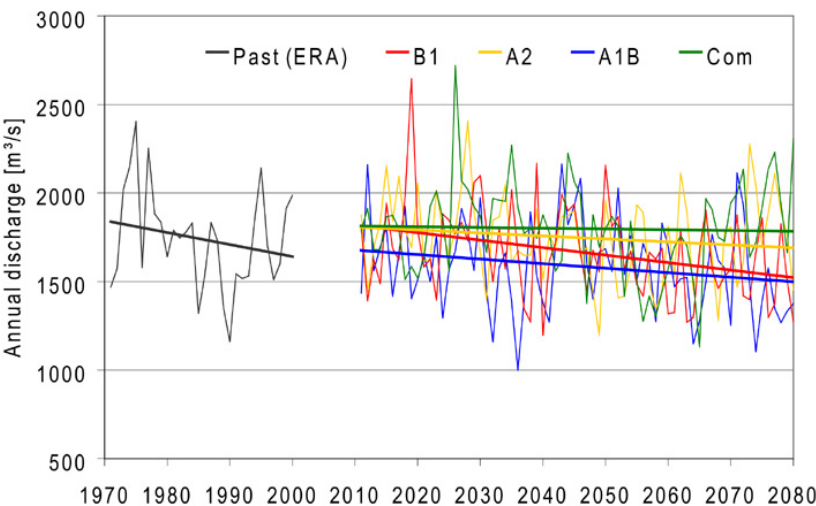

Figure 9. Development of the mean annual discharge in the UDRB for the past and the four scenarios from 1971-2080.

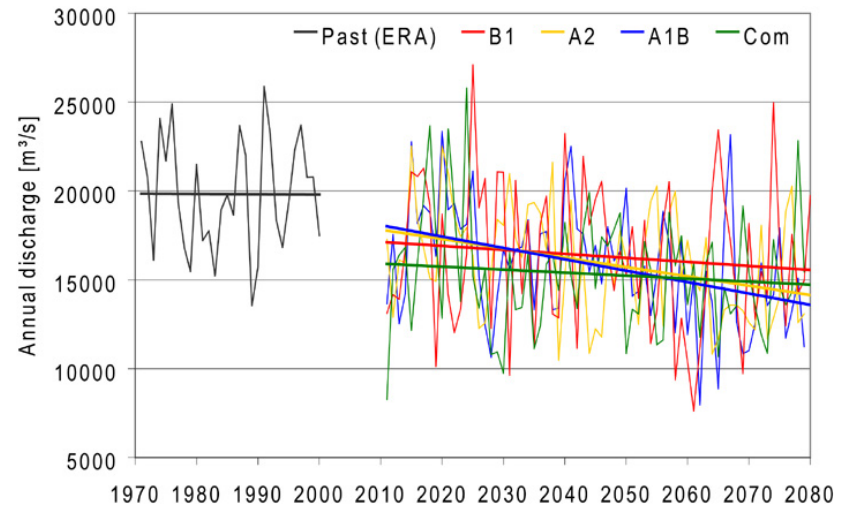

Figure 10. Development of the mean annual discharge in the UBRB for the past and the four scenarios from 1971-2080.

climate change on the water balance, the hydrological time series were analysed in detail for the period from 2011 to 2080.

In the UDRB as well as the UBRB a reduction of the mean annual runoff is simulated (Figs. 9 and 10). Hence, the water availability in both catchments is decreasing in 


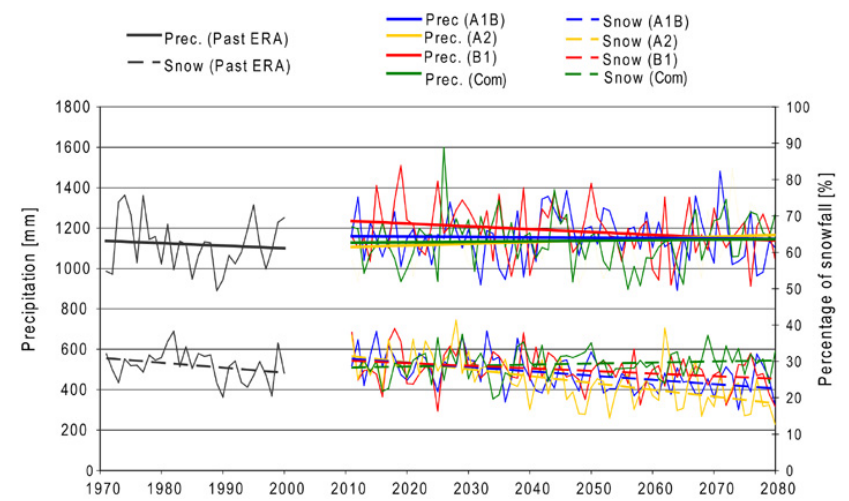

Figure 11. Development of the annual precipitation sum and the percentage of snow precipitation in the UDRB for the past and the four IPCC SRES scenarios from 1971-2080.

average according to the future simulations. The magnitude of the trends varies according to the chosen IPCC SRES scenario. While there is no significant trend for the commitment scenario, the strongest decrease is modelled for B1 in the UDRB. In the Asian test site a decrease is simulated for all four scenarios, which rises from the commitment to the A1B scenario conditions. Reasons for the reduction can be found in the precipitation sum on the one hand. Whereas in the UBRB precipitation is becoming less in all four scenarios (see Chapter 2), there is no significant trend in the UDRB except for the $\mathrm{B} 1$ scenario with a precipitation decrease. Not only the precipitation sum is of importance for the water availability but also the precipitation phase plays an essential role because of the temporal storage function of snow and ice. The decreasing trend of the percentage of snowfall during the past period from 1971 to 2000 continues in both basins as well as for all four scenarios except the commitment run (Figs. 11 and 12). The magnitude of the trend is related to the different conditions according to the SRES scenarios with different increasing air temperatures (see Chapter 2). Hence for the commitment model run without increasing emissions in the future a slight increase of snowfall is simulated. On the other hand, an increase in evapotranspiration also causes a reduced runoff. The increasing temperatures as well as longer vegetation periods result in an increasing evapotranspiration sum in both basins, where the trend is clear for all scenarios except the A2 scenario conditions in the UDRB.

In the next step, the average runoff pattern from the climate periods from 2011 to 2040 and from 2051 to 2080 is compared to the past period from 1971 to 2000 , where the reduction of water availability described above is confirmed. Furthermore the average from 2011 to 2040 and from 2051 to 2080 of the mentioned output parameters is analysed in its spatial distribution, focussing on the $\mathrm{B} 1$ and the $\mathrm{A} 1 \mathrm{~B}$ scenario results. Figure 13 shows the difference of the future values to the past. In the UDRB in both scenarios in the

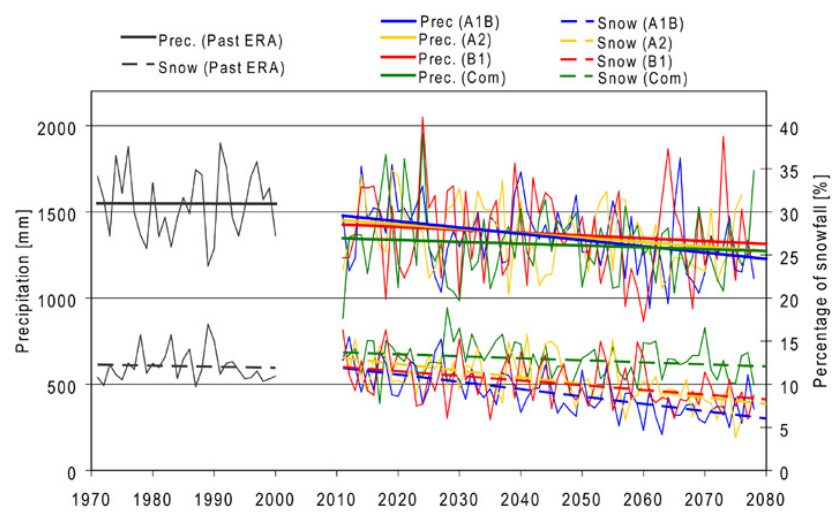

Figure 12. Development of the annual precipitation sum and the percentage of snow precipitation in the UBRB for the past and the four IPCC SRES scenarios from 1971-2080.

western parts, especially in the southwest, a decrease in runoff can be seen whereas in the eastern parts an increase in runoff is simulated. Reasons are the different precipitation patterns which correspond to the runoff. Moreover the annual evapotranspiration increases in the low and high mountain ranges due to higher temperatures and accordingly longer growing seasons whereas in the lower valleys, especially in the northern parts of the watershed, there is a small decrease modelled which might be caused by water stress of the plants.

The UBRB is also divided into regions with increasing water availability in the Tibetan parts, whereas in Assam in India the runoff will decrease according to the scenarios. Again this represents the precipitation pattern. Evapotranspiration is determined by the water availability due to precipitation. With increasing precipitation in the Tibetan parts the evapotranspiration also increases a little whereas in Assam both an increasing as well as a decreasing trend is simulated.

Finally, the monthly runoff was studied to find out seasonal changes in the water availability in the future. Therefore the mean runoff of the climate periods mentioned above is compared. According to all scenarios the runoff will decrease in the UDRB (Fig. 14) especially during the summer month. This trend goes on in the last period of the scenario time. As this is the growing season it is especially of importance for agriculture but also for energy production and shipping in the Danube, not only in the Upper basin, but also in the attached regions of Austria and Hungary. In the UBRB runoff will decrease in all four scenarios in the first 30 years of the modelled future period, especially during the summer months. The decreasing trend is going on in the second period from 2051 to 2080 . Regarding the annual runoff peak, no clear trend can be seen. Figure 15 shows the mean monthly runoff in the UBRB for the three periods and the four different scenarios.

Besides the decrease of snow precipitation, the influence of glacier melt on runoff was analysed for the test site of 

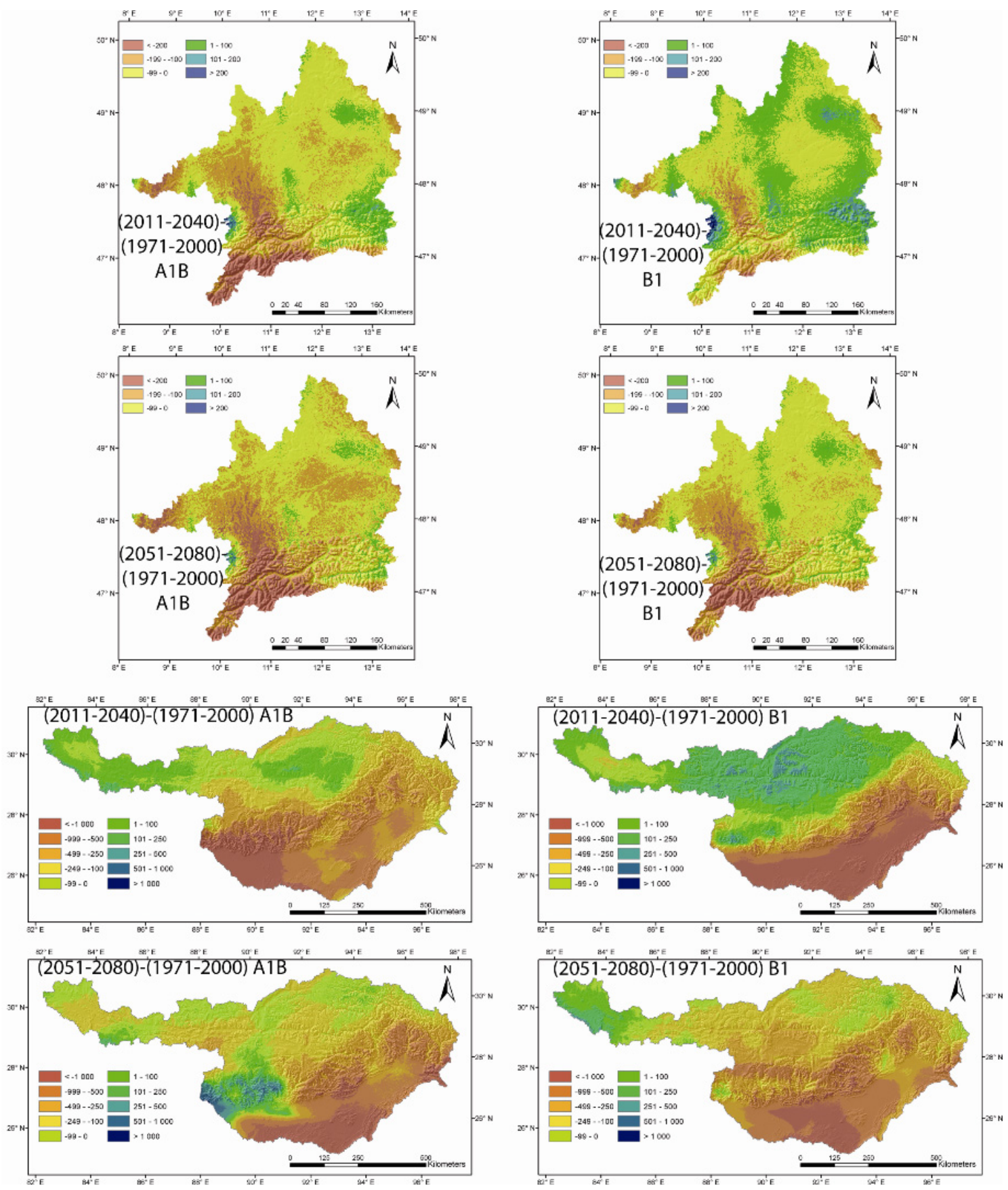

Figure 13. Difference of the mean annual runoff [mm] of the two future 30-years periods from 2011-2040 and 2051-2080 according to the A1B and B1 scenario compared to the past 30-years period from 1971 to 2000 in the UDRB (top) and the UBRB (bottom).

the Lhasa River catchment. In comparing model run outputs with model run outputs without considering glaciers, the amount of ice melt of the glaciers can be determined. Due to increasing air temperatures the melting periods will be longer in the future, so that the influence of ice melt during the future period from 2011 to 2040 increases compared to the past. Afterwards the influence goes down because of the melting away of the glaciers and their water reservoirs
(Fig. 16). As the influence of glacier runoff is little compared to the influence of the monsoon precipitation this is only of importance during periods without precipitation in spring and autumn (Prasch, 2010). This confirms the results for the UDRB (GLOWA Danube, 2010) where the influence of glaciers, which is only relevant in alpine headwatersheds, will further go down because of the melt out of the glaciers. 


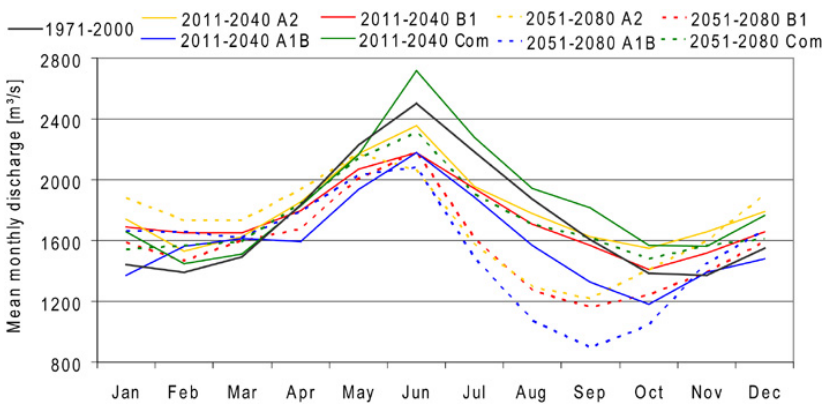

Figure 14. Developing of the mean monthly discharge in the UDRB for the past from 1971-2000 in comparison to the 30-years period from 2011-2040 and 2051-2080.

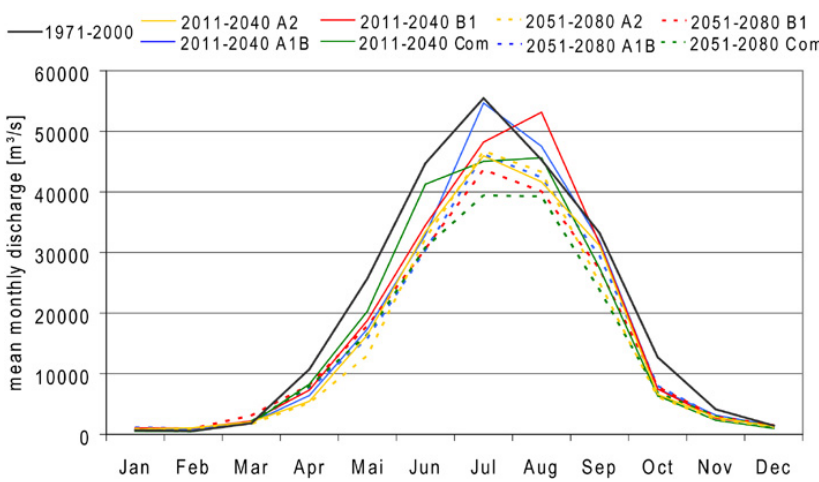

Figure 15. Developing of the mean monthly discharge in the UBRB for the past from 1971-2000 in comparison to the 30-years period from 2011-2040 and 2051-2080.

\section{Contributions to sustainable IWRM}

Under the assumption that climate will develop according to the CLM ECHAM 5 model output due to the chosen IPCC SRES scenarios, climate change will have a significant impact on the hydrological dynamics of the water balance in the UDRB and the UBRB. There will be less water available in both the UDRB and the UBRB. Reasons for the decrease predominantly are less precipitation and higher evapotranspiration due to rising air temperatures. Accordingly, snowfall will decrease and the glaciers will melt out in the headwatersheds. However, the glacier melt water only has a small influence on the water availability in the populated mountain forelands. Its amount will not suffice to compensate less water in the rivers, because the influence is small compared to precipitation. Besides various other impacts, there will be less water available for hydropower production, which is the main renewable power source in the UDRB at the moment. Furthermore, the changes will affect agriculture. In regions with higher elevation, the growing season will be longer due to higher temperatures than in the past. In combination with increasing precipitation as it is simulated for Tibetan parts in the UBRB as well as for the Eastern Alps in the UDRB,

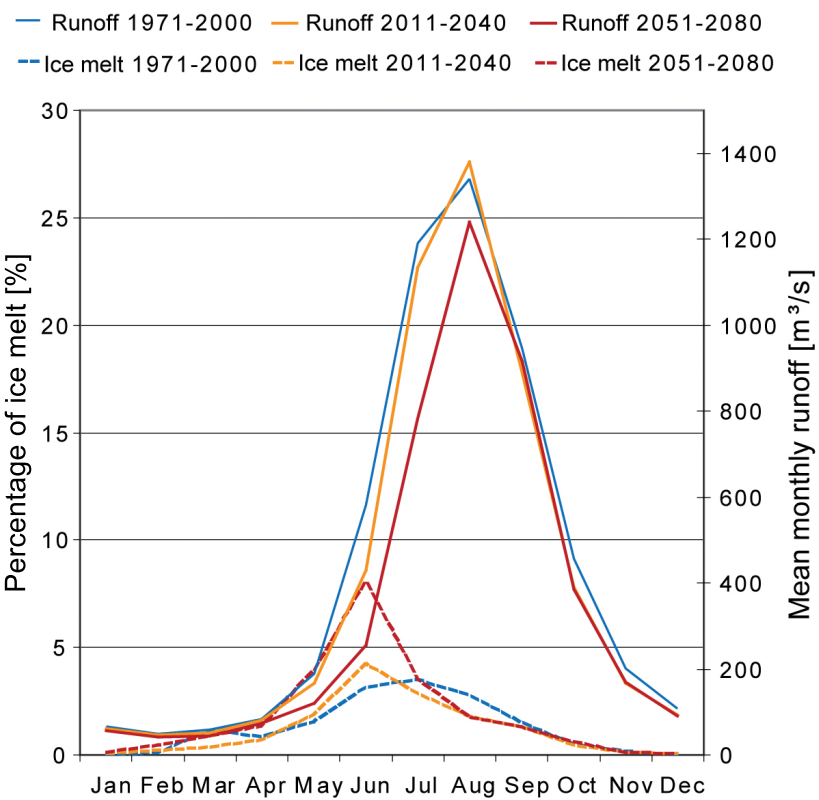

Figure 16. Development of the percentage of ice melt on the mean monthly discharge in the Lhasa River catchment for the 30-yearsperiods from 1971-2000, from 2011-2040 and from 2051-2080 according to the A1B scenario.

the situation for agriculture might improve. On the contrary, drought stress might increase in the valleys of the Danube or the Brahmaputra in Assam due to higher temperatures, more evapotranspiration and partly less precipitation. To be able to adapt to the impact of climate change, this has to be considered in future plans, e.g. for the construction of hydro power plants or landuse changes in the IWRMS.

\section{Conclusions and recommendations}

The physically based distributed hydrological model DANUBIA was applied successfully not only in the UDRB but also in the UBRB. The environmental and climatic conditions in both watersheds differ considerably. Based on the available historic data validated hydrological model results are delivered for both catchments, so that the transferability of the approach, which was developed in Europe, to Asia was successfully demonstrated. Furthermore, the model results for the past justify the application for future scenarios in both catchments, using future regional climate model output data of the CLM as meteorological drivers. Although several input data are required to apply DANUBIA, the model setting allows a distributed simulation of the impact of climate change on the water balance with a high spatial and temporal resolution. Hence, the time series of water cycle components for historical and future climatic conditions for both the UDRB and the UBRB enable the determination of the regional impact of climate change on the hydrologic cycle. In this way, the development of the Integrated Water 
Resources Management System (IWRMS) as one of the ultimate outcomes of BRAHMATWINN for the adaptation to climate change impacts is based on the results of DANUBIA together with the socio-economic results (see Chapter 4). In a next step the proposed adaptation strategies should be simulated in further DANUBIA model runs to determine their effectiveness and efficiency in an integrated approach. For instance, the effect of land use changes on runoff and evapotranspiration could be assessed with a different land use classification as input.

Acknowledgements. The authors thank the European Commission for funding BRAHMATWINN within the Sixth Framework Program (FP6). The project GLOWA-Danube, funded by the BMBF, the State of Bavaria and the Ludwig-Maximilians-Universität Munich, and especially Markus Weber is acknowledged for their cooperation.

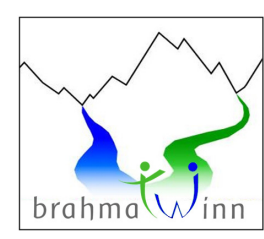

The interdisciplinary BRAHMATWINN EC-project carried out between 2006-2009 by European and Asian research teams in the UDRB and in the UBRB enhanced capacities and supported the implementation of sustainable Integrated Land and Water Resources Management (ILWRM).

\section{References}

Barnett, T. P., Adam, J. C., and Lettenmaier, D. P.: Potential impacts of a warming climate on water availability in snow-dominated regions, Nature, 438, 303-309, 2005.

Boston University: NASA TERRA/MODIS HDF-EOS MOD12Q1 V004 Land Cover Product Binary Data, Eurasia subset, IGBP Class Scheme, http://duckwater.bu.edu/lc/mod12q1.html (last access: 26 April 2007), 2004.

FAO-UNESCO: The Digital Soil Map of the World, Version 3.6, 2003.

Flügel, W.-A.: Hydrological Response Units (HRU) as modelling entities for hydrological river basin simulation and their methodological potential for modelling complex environmental process systems - Results from the Sieg catchment, Die Erde, 127, 42-62, 1996.

Gerstengarbe, F.-W.: Conditions and Potentials for Climate Projections, in: Climate of the 21st Century: Changes and Risks, edited by: Lozan, J. L., Graß1, H., and Hupfer, P., Hamburg, 2001.

GLOWA-Danube: http://www.glowa-danube.de (last access: 3 November 2010), 2010.

Jain, S., Agarwal, P., and Singh, V.: Hydrology and Water Resources of India, Springer, Dodrecht, 2007.

Jarvis, A., Reuter, H. I., Nelson, A., and Guevara, E.: Holefilled seamless SRTM data V3, International Centre for Tropical Agriculture (CIAT), http://srtm.csi.cgiar.org (last access: 2 March 2007), 2006.
Leavesley, G. H., Lichty, R. W., Troutman, B. M., and Saindon, L. G.: Precipitation - runoff Modeling System - Users Manual, US Geological Survey Water-Resources Investigations Report 83, 4238, 207 pp., 1983.

Lee, H., Silvapalan, M., and Zehe, E.: Representative elementary watershed (REW) approach, a new blueprint to distributed hydrologic modelling at the catchment scale, in: Predictions in Ungauged Basins: International Perspectives of State of the Art and Pathways Forward, edited by: Franks, S. W., Silvapalan, M., Takeuchi, K., and Tachikawa, Y., IAHS Press, Wallingford, Oxen, UK, 2005.

Marke, T.: Development and Application of a Model Interface to couple Regional Climate Models with Land Surface Models for Climate Change Risk Assessment in the Upper Danube Watershed, Dissertation der Fakultät für Geowissenschaften, Digitale Hochschulschriften der LMU München, 188, available at: http: //edoc.ub.uni-muenchen.de/9162/, München, 2008.

Mauser, W. and Bach, H.: PROMET - Large scale distributed hydrological modelling to study the impact of climate change on the water flows of mountain watersheds, J. Hydrol., 376, 362-377, 2009.

Mauser, W. and Ludwig, R.: GLOWA-DANUBE - a research concept to develop integrative techniques, scenarios and strategies regarding global changes of the water cycle, in: Climatic Change: Implications for the Hydrological Cycle and for Water Management, Advances in Global Change Research, edited by: Beniston, M., Vol. 10, Kluwer Academic Publishers, Dordrecht and Boston, 171-188, 2002.

Nash, J. E. and Sutcliffe, J. V.: River flow forecasting through conceptual models, a discussion of principles, J. Hydrol., 227, 33-51, 1970.

Oerlemans, J.: Minimal Glacier Models, Utrecht, 2008.

Prasch, M.: Distributed Process Oriented Modelling of the Future Impact of Glacier Melt Water on Runoff in the Lhasa River Basin in Tibet, Dissertation der Fakultät für Geowissenschaften der LMU München, 228 pp., 2010.

Singh, V. P., Sharma, N., and Ojha, C. Sh. P.: The Brahmaputra Basin Water Resources, Water Science and Technology Library, Vol. 47, Dodrecht, 2004.

WDC: Chinese Glacier Inventory of the World Data Center For Glaciology and Geocryology, Lanzhou, China, http://wdcdgg. westgis.ac.cn/DATABASE/Glacier/glacier_inventory.asp (last access: 17 August 2009), 2009.

Weber, M., Prasch, M., Strasser, U., und Mauser, W.: Embedded grid-modelling of 506 glaciers in the upper Danube basin, Geophys. Res. Abstr., 10, EGU2008-A-01029, 2008.

Weber, M., Braun, L., Mauser, W., and Prasch, M.: Die Bedeutung der Gletscherschmelze für den Abfluss der Donau gegenwärtig und in der Zukunft, The relevance of glacier melt for the Upper Danube River discharge today and in the future, Mitteilungsblatt des hydrographischen Dienstes in Österreich, No. 86, 1-29, 2009. 